\title{
Memory and accurate processing brain rehabilitation for the elderly: LEGO robot and iPad case study
}

\author{
Leire Lopez-Samaniego *, Begonya Garcia-Zapirain and Amaia Mendez-Zorrilla \\ DeustoTech Life [eVIDA] Faculty of Engineering University of Deusto, Avda de las Universidades 24, \\ Bilbao, Spain
}

\begin{abstract}
This paper presents the results of research that applies cognitive therapies associated with memory and mathematical problem-solving in elderly people. The exercises are programmed in an iPad and can be performed both from the Tablet and in an interactive format with a LEGO robot. The system has been tested with 2 men and 7 women over the age of 65 who have slight physical and cognitive impairment. Evaluation with the SUS resulted in a mean of 48.45 with a standard deviation of 5.82. The score of overall satisfaction was 84.37 with a standard deviation of 18.6. Interaction with the touch screen caused some usability problems due to the elderly people's visual difficulties and clicking accuracy. Future versions will include visualization with more color contrast and less use of the keyboard.
\end{abstract}

Keywords: iPad, cognitive rehabilitation, objective-C, system usability scale (SUS)

\section{Introduction}

In recent decades, life expectancy in developed societies has increased. As a result, there is an increasing number of elderly people. This aging population has been one of man's greatest achievements but is also one of the greatest challenges in the $21^{\text {st }}$ century. By mid-century, a high percentage of the population will belong to this age group due to the decrease in the birth-rate and the increase in life expectancy. These predictions have caused alarm and prompted research to find methods to encourage proper aging in order to make future elders more independent.

The process of aging starts at the moment of birth and lasts until the last moment in life. During this process, the different capacities begin developing in childhood, reaching their peak in early adulthood and then begin to decline. This deterioration is natural but may also be influenced by each person's lifestyle, as influenced by diet, physical activity, alcoholism, and smoking.

In order to prevent early aging and delay the natural aging process, "active aging" is now being tested. This concept refers to staying active during one's lifetime by doing activities that boost physical, psychological, and social well-being in order to extend productivity, quality of life, and life

\footnotetext{
${ }^{*}$ Corresponding author: Leire Lopez-Samaniego, DeustoTech Life [eVIDA] Faculty of Engineering University of Deusto, Avda de las Universidades 24, Bilbao, Spain. Tel.: +34 6199672 23; E-mail: mbgarciazapi@deusto.es.
} 
expectancy well into old age. Some of the traditionally recommended "active aging" activities are walking, writing, reading, speaking, solving mathematical problems, crossword puzzles, etc. There are other technologies which are not thought to help people, although they actually do by boosting capabilities such as memory, concentration, spatial vision, and problem-solving. One of these technologies includes certain videogames. These games involve situations that can only be solved if the player focuses on the scenario's small details, remembering some of the previous parts of the game, solving puzzles or even having to coordinate with a partner and doing multitasking activities.

\section{Background}

In order to analyze the research and technologies in this field, we must first take into account all the studies that have been conducted to find out whether or not cognitive improvement could boost rehabilitation of patients with diseases such as schizophrenia [1], individuals with traumatic brain injury (TBI) [2], or even cognitive disorders in elderly people [3-5]. There is also some research on cognitive skills improvement after neurological issues from TBI, stroke, and neurodegenerative disorders [6-8]. Some research has shown the benefits of the use of virtual reality (VR) technology for rehabilitation of people with TBI, neurological disorders, learning disabilities, muscle-skeletal problems, stroke-induced paralysis, and cognitive deficits [9-12].

Some technologies have been developed to help elderly people with cognitive disabilities, focusing on maintaining the current level of their cognitive skills. One such example is the use of artificial intelligence to assist them [13].

Apart from the traditional methods to improve or maintain cognitive skills, there are some technological solutions, such as iPad-assisted cognitive training via games for users suffering from schizophrenia, a multimodal guidance system with a graphical user interface (GUI) for people with Down Syndrome and developmental disabilities to recover motor and visual-spatial abilities [14-18].

It is important to note that these games are complemented by the use of a LEGO robot from another project, which means all the projects involving SARs (Socially Assistive Robots) must be taken into account $[19,20]$.

Hence, due to the good results obtained in different studies using SARs, such as PARO, a brand name for a therapeutic robot used for several purposes (as a pet or as a catalyst to improve social interaction of the elderly mentally ill) [21-24], or robots used for physical rehabilitation following strokes [25-28]; the decision was made to merge an IPad with a LEGO robot.

\section{Methodology}

\subsection{Participants}

For this experiment, nine elderly people, two men and seven women, between 66-89 years of age from the La Real Casa de la Misericordia nursing home in Bilbao, Spain, were randomly chosen by a psychologist and a physiotherapist. It is important to note that six of them needed a wheelchair; moreover, two of those 6 wheelchair users showed moderate cognitive impairment.

Inclusion Criteria: people from a nursing home with no or partial dependence for autonomous life.

Exclusion Criteria: people having severe cognitive impairment and/or physical movement restrictions causing them to be bedridden. 
This research was conducted in compliance with the Code of Ethics which includes an informed written consent signed by each participant. In addition, all participants were informed of the study aims and protocols.

\subsection{Technologies}

\subsubsection{Hardware}

The hardware used for this project consists of an iPad (in order to provide an interface), the LEGO NXT Intelligent Brick from the Mindstorm kit (in order to build the robot) and the Teensy 2.0 board (in order to establish communication between the two devices). All those devices connected together constitute the ALECSA robot of this project.

\subsubsection{Software}

The software used for this project was the Xcode IDE for programming the iPad mini, the Labview high-level programming environment to program the NXT brick, and the Arduino programming environment for the Teensy 2.0 board.

\section{System design}

The schema shown in Fig. 1 illustrates how the elderly interact with the iPad, which would allow them to play with the NXT brick in order to perform the 3 different cognitive games and receive feedback from the robot.

The games begin with a mathematical exercise in which the user is asked to do some sums, subtractions and multiplications. The second game is related to memory skills in which the user has to memorize every word from a list and could possibly be asked to solve a mathematical problem, depending on the level of difficulty of the game.

In Fig. 2, the high-level design of the system can be seen. The lower part shows the structure of the hardware while the upper part includes a diagram of the iPad's software.

In order to build this interface (GUI) and its controller, it was necessary to know the user requirements, which were indicated by La Real Casa de la Misericordia nursing home. These included requirements for the design and activities. When the activity is completed, its action results in an event which sends a MIDI command, which are the commands send by the Teensy 2.0 board to the NXT brick, in order for the subject to have feedback from the robot.

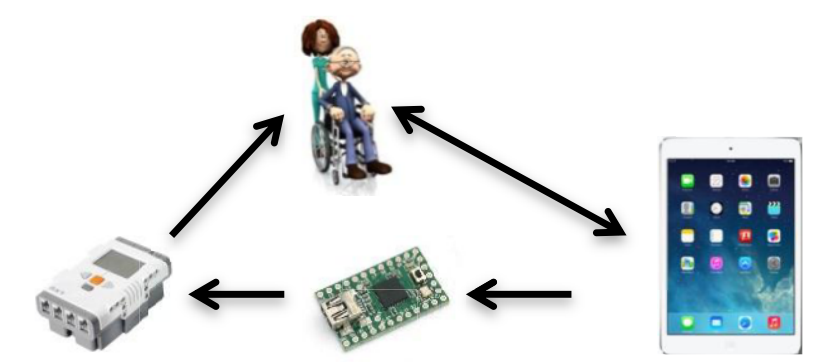

Fig. 1. General schema of the system. The hardware used from left to right includes the LEGO NXT brick, a Teensy 2.0 and an iPad. 
The diagram of the structure in the low part of Figure 2 includes both the NXT Brick and the iPad. Blocks A, B, D, E, G and $\mathrm{H}$ refer to this so the requirements provided by La Real Casa de la Misericordia could be taken into account for the robot and the iPad. According to these requirements, the structure was built and the mechanical design and assembly were carried out, including the need for extra material apart from the Mindstorm kit and the iPad. This extra material refers to the multiplexors needed to use 6 servomotors instead of 3 and the LiPo batteries required for the multiplexors.

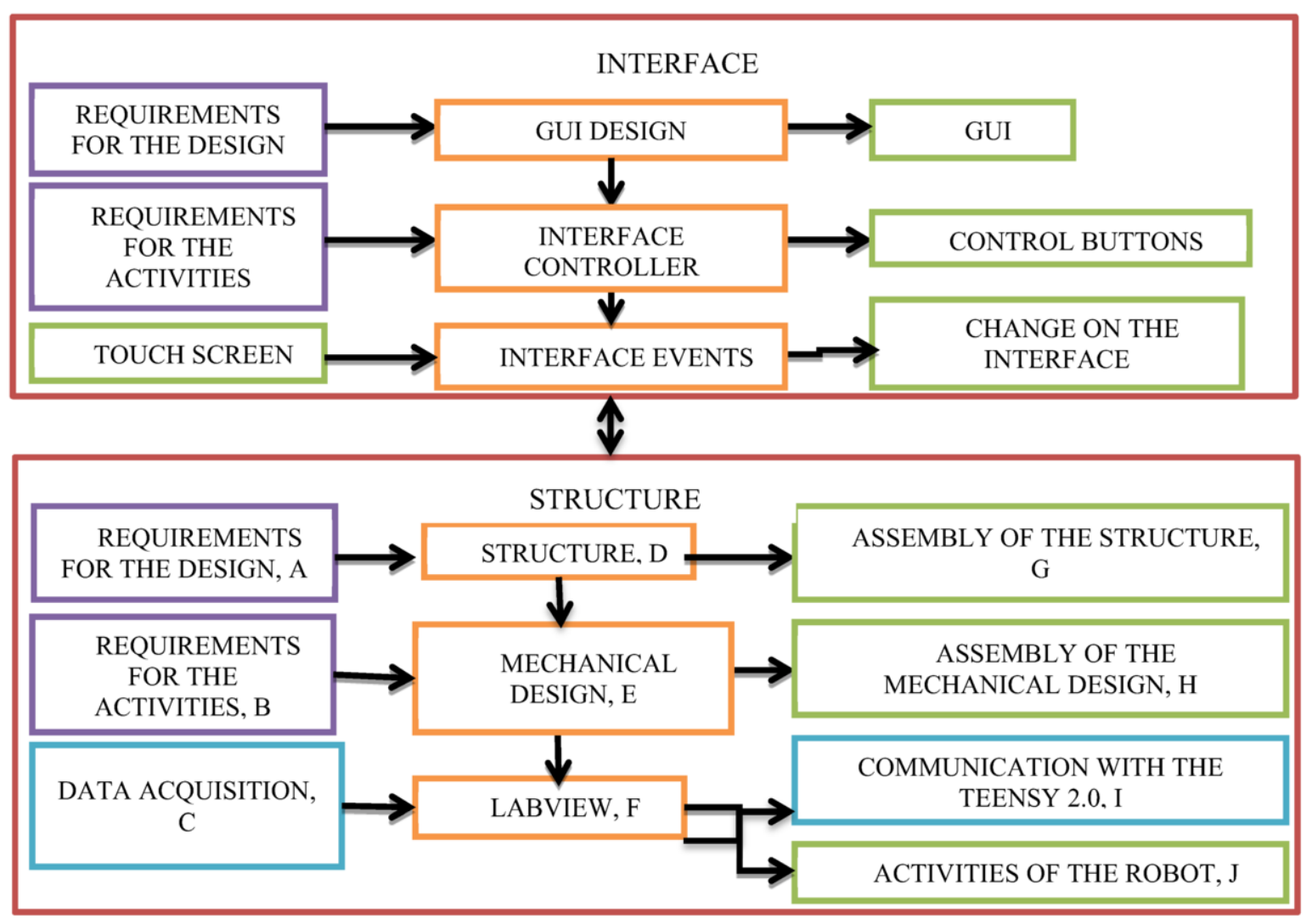

Fig. 2. High-level design.

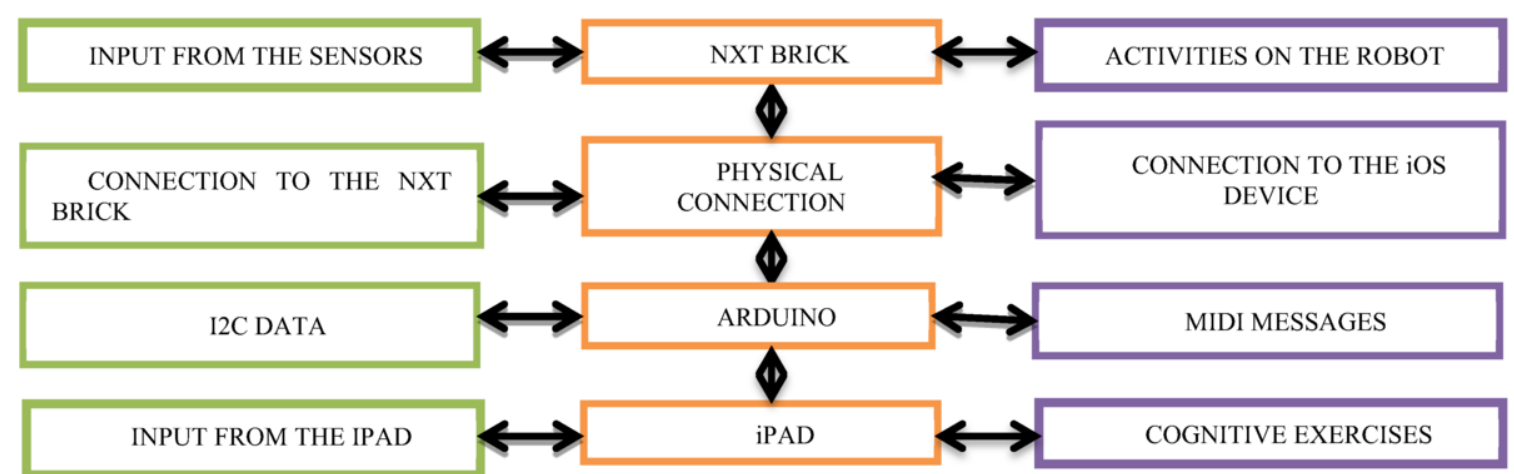

Fig. 3. Low-level design. 


\section{Results}

The system evaluation was performed in a real use situation, an example of which is shown in Fig. 4.

Due to the fact that the cognitive rehabilitation exercises can be performed on the robot using it as support for the iPad or placing it on a table, each user participated in the evaluation of the system by doing the exercise both ways.

After the exercises, a System Usability Scale (SUS) questionnaire and an opinion questionnaire were completed, the last one of which was divided into appearance, activity, motivation, instructions, use and general satisfaction.
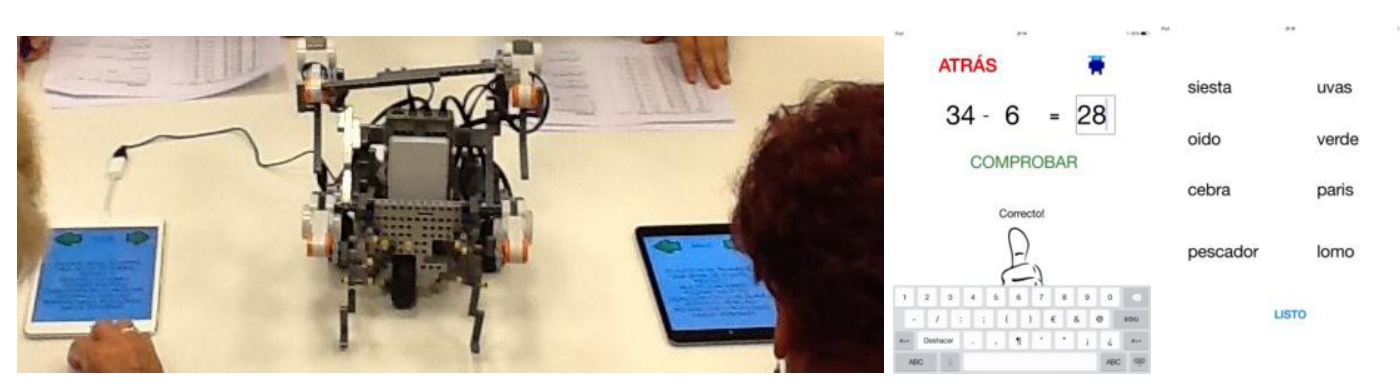

Fig. 4. Users with the robot and iPad (left). Mathematical exercise interface (center). Memory exercise interface (right).

Table 1

SUS assessment test

\begin{tabular}{lllll}
\hline $\begin{array}{l}\text { SUS } \\
\text { QUESTIONNAIRE }\end{array}$ & MEAN (over 100) & $\begin{array}{l}\text { STANDARD } \\
\text { DEVIATION }\end{array}$ & MINIMUM & MAXIMUM \\
\hline USABILITY & 48.75 & 5.82 & 42.50 & 57.50 \\
\hline
\end{tabular}

Table 2

Opinion questionnaire

\begin{tabular}{|c|c|c|c|c|}
\hline $\begin{array}{l}\text { OPINION } \\
\text { QUESTIONNAIRE }\end{array}$ & $\begin{array}{l}\text { MEAN (over } \\
100)\end{array}$ & $\begin{array}{l}\text { STANDARD } \\
\text { DEVIATION }\end{array}$ & MINIMUM & MAXIMUM \\
\hline GENERAL SATISFACTION & 84.37 & 18.60 & 50 & 100 \\
\hline INSTRUCTIONS AND USE & 70.31 & 7.28 & 56.25 & 81.25 \\
\hline APPEARANCE & 72.50 & 7.07 & 60 & 80 \\
\hline ACTIVITY & 87.50 & 9.45 & 68.75 & 100 \\
\hline MOTIVATION & 84.38 & 18.60 & 50 & 100 \\
\hline
\end{tabular}

As it can be seen in Table 1, the mean usability score is the lowest (mean, 48.75, SD=5.82), indicating a big difference in comparison to all the other sections of the opinion questionnaire. In addition, as Table 2 shows, the users' evaluation of their "general satisfaction" toward the whole system, including both the task and the robot, shows high scores, with a mean of $84.37(\mathrm{SD}=5.82)$ over 100

The appearance, instructions and use variables are the second lowest scores, showing the following mean scores respectively: $72.50(\mathrm{SD}=7.70)$ and $70.31(\mathrm{SD}=7.28)$. On the other hand, the results show that the participants' opinion of the application motivates them to do cognitive rehabilitation, with a high subject motivation mean (mean $84.38, \mathrm{SD}=18.60$ ). Their opinion concerning the benefit of the 
cognitive activities carried out by the end users and people of their same age is gathered under the "Activities" heading. This score was the highest, with a mean of 87.50 (SD=9.45).

We highlight the following comments which were repeated by several participants responding to the qualitative opinions of the iPad application on the questionnaire:

- The mathematical activities need to be in column format and not in lines as it is easier to proceed.

- The numbers in the arithmetic activities were the right size but the signs were not so clear.

- Following each arithmetic operation, the message of "correct" overlapped the following activity.

- In memory exercises, end users considered that the requirement to type each word obstructed the memory activity.

\section{Discussion and conclusions}

Of the results explained in the previous section, the low scores in the SUS questionnaire clearly show that the end users (elderly people) face some difficulties performing the cognitive activities on the iPad. The reasons for this could be as follow: (1) the interaction with the multi-touch device creates some problems as the users press the screen at more than one point with several fingers, (2) some of the instructions may need to be more graphical, using objects and figures instead of words, (3) there is little colour contrast in the interface which makes it hard to use for people with visual impairment, and (4) touchable keyboards should be avoided as the users are not familiarized with the letter order in them.

However, the higher scores in sections of the opinion questionnaire show that elderly people like the system despite having problems using it. The problems are likely related to the difficulties in following the instructions and autonomous use of the system. On the other hand, it should be underscored that the end users see the potential benefits of the application for their cognitive maintenance and that of other people. In the following lines, we explain each section separately.

The end users' positive opinion, expressed as a high level of general satisfaction in the corresponding section, indicates that the application arouses the curiosity of the majority, prompting them to use a technological device such as the iPad and the LEGO SARs. A similar conclusion was reached in other studies $[29,30]$, where it was found that the users consider this kind of technology more enjoyable. Moreover, it is clear that the game playing approach of the memory activities and accurate processing promotes satisfaction as the end users do not have the sensation of being in a standard rehabilitation session.

Motivation was a well-valued parameter with high variability in the users' evaluations, ranging between 50 and 100 points. This may be due to the fact that there are great differences in the users' cognitive states: some of the participants may have found the exercises challenging because they felt that their cognitive status was good enough, but others may have felt that the exercises were too difficult for their state. For example, before beginning the memory exercises, one woman stated: "I cannot do these exercises; I had an accident and I have no memory". This was also seen in some studies [29], where the conclusions highlighted the vital importance of choosing the appropriate level of difficulty for each user rather using the same one for all of them.

Although the instructions and use variable obtained a reasonable score, there was a general recommendation to replace text for figures and more visual icons. In this manner, elderly people can focus on doing the exercise, since the initial training would be very visual, graphic, and simple. Finally, the iPad screen is the equivalent of the robot's face and therefore the more agreeable and attractive the interface is the more participants will feel that it is fun. 
Regarding the activity and its benefits, it is surprising that most of the answers showed that users valued the exercises as effective for themselves but difficult or impossible for other persons of their own age. In other words, the users felt superior the vast majority of the time. When contrasting this with the psychologist from La Real Casa de la Misericordia, this comparison with others seems to be a common practice.

Finally, although playing the cognitive rehabilitation games could be made more attractive and motivating by placing the iPad on the robot, there was an issue due to the pressure exerted when touching the screen. If the iPad is placed in a position where the user presses the buttons which are close to the robot base, the tablet may fall and not only shatter the screen but also startle the user. Hence, for elderly people, the cognitive games are likely to function better if the iPad were used on a table rather than on the robot.

\section{Acknowledgement}

We are grateful for the inestimable collaboration of La Real Casa de la Misericordia nursing home in Bilbao and that of the sociocultural promotion member, Irantzu Kareaga, and physiotherapist, Leire Basoa. Herewith we specially thank our colleague, Alejandro Ozaita-Araico, for his support and help during the entire process.

\section{References}

[1] W. Spaulding, S. Fleming, D. Reed, M. Sullivan, D. Storzbach and M. Lam, Cognitive functioning in schizophrenia: Implications for psychiatric rehabilitation, Schizophr. Bull. 25 (1999), 275-289.

[2] K. Ragnarsson, L. Moses, W. Clarke, J. Daling, S. Garber, C. Gustafson, A. Holland, B. Jordan, J. Parker, M. Riddle, E. Roth, M. Seltzer, S. Small, B. Therrien, B. Wexler and B. Yawn, Rehabilitation of persons with traumatic brain injury, Journal Am. Med. Assoc. 282 (1999), 974-983.

[3] C.D.C. Altermann, A.S. Martins, F.P. Carpes and P.B. Mello-Carpes, Influence of mental practice and movement observation on motor memory, cognitive function and motor performance in the elderly, Brazilian J. Phys. Ther. 18 (2014), 201-209.

[4] K. Rockwood, B. Joyce and P. Stolee, Use of goal attainment scaling in measuring clinically important change in cognitive rehabilitation patients, J. Clin. Epidemiol. 50 (1997), 581-588.

[5] G.W. Rebok, K. Ball, L.T. Guey, R.N. Jones, H.-Y. Kim, J.W. King, M. Marsiske, J.N. Morris, S. L. Tennstedt, F.W. Unverzagt and S.L. Willis, Ten-year effects of the advanced cognitive training for independent and vital elderly cognitive training trial on cognition and everyday functioning in older adults, J. Am. Geriatr. Soc. 62 (2014), 16-24.

[6] C. Miniussi, S.F. Cappa, L.G. Cohen, A. Floel, F. Fregni, M.A. Nitsche, M. Oliveri, A. Pascual-Leone, W. Paulus, A. Priori and V. Walsh, Efficacy of repetitive transcranial magnetic stimulation/transcranial direct current stimulation in cognitive neurorehabilitation, Brain Stimul. 1 (2008), 326-336.

[7] R.J. Heruti, A. Lusky, V. Barell, A. Ohry and A. Adunsky, Cognitive status at admission: Does it affect the rehabilitation outcome of elderly patients with hip fracture? Arch. Phys. Med. Rehabil. 80 (1999), 432-436.

[8] C. Rosano, E.M. Simonsick, T.B. Harris, S.B. Kritchevsky, J. Brach, M. Visser, K. Yaffe and A.B. Newman, Association between physical and cognitive function in healthy elderly: The health, aging and body composition study, Neuroepidemiology 24 (2005), 8-14.

[9] M.T. Schultheis and A.A. Rizzo, The application of virtual reality technology in rehabilitation, Rehabil. Psychol. 46 (2001), 296-311.

[10] A.A. Rizzo, M. Schultheis, K.A. Kerns and C. Mateer, Analysis of assets for virtual reality applications in neuropsychology, Neuropsychol. Rehabil. 14 (2004), 207-239.

[11] G. Burdea, Virtual rehabilitation-benefits and challenges, Methods Inf. Med. 42 (2003), 519-523.

[12] A.A. Rizzo, J.G. Buckwalter, T. Bowerly, C. Van Der Zaag, L. Humphrey, U. Neumann, C. Chua, C. Kyriakakis, A. Van Rooyen and D. Sisemore, The virtual classroom: A virtual reality environment for the assessment and rehabilitation of attention deficits, Cyber Psychology Behav. 3 (2000), 3483-499. 
[13] M.E. Pollack, Intelligent technology for an aging population: The use of AI to assist elders with cognitive impairment, AI Magazine 26 (2005), 9-24.

[14] J. Dang, J.T. Zhang, Z.W. Guo, W.H. Lu, J. Cai, Z.Y. Shi and C. Zhang, A pilot study of ipad-assisted cognitive training for schizophrenia, Arch. Psychiatr. Nurs. 28 (2014), 197-199.

[15] M. Covarrubias, E. Gatti, M. Bordegoni, U. Cugini and A. Mansutti, Improving manual skills in persons with disabilities (PWD) through a multimodal assistance system, Disabil. Rehabil. Assist. Technol. 9 (2014), 335-343.

[16] C. Stephanidis, Universal Acess in Human Computer Interaction, Coping with Diversity, Springer Berlin Heidelberg, 4554 Berlin, Heidelberg, 2007.

[17] B. Levine, D.T. Stuss, G. Winocur, M.A. Binns, L. Fahy, M. Mandic, K. Bridges and I.H. Robertson, Cognitive rehabilitation in the elderly: Effects on strategic behavior in relation to goal management, J. Int. Neuropsychol. Soc. 13 (2007), 143-152.

[18] F.I.M. Craik, G. Winocur, H. Palmer, M.A. Binns, M. Edwards, K. Bridges, P. Glazer, R. Chavannes and D.T. Stuss, Cognitive rehabilitation in the elderly: Effects on memory, J. Int. Neuropsychol. Soc. 13 (2007), 132-142.

[19] J. Fasola and M.J. Mataric, Using socially assistive human-robot interaction to motivate physical exercise for older adults, Fellow IEEE 100 (2012), 2512-2526.

[20] W.-L. Chang, S. Sabanovic and L. Huber, Use of seal-like robot PARO in sensory group therapy for older adults with dementia, Proc. 8TH ACM/IEEE Int. Conf. Human-Robot Interact, 2013, 101-102.

[21] T. Shibata, Y. Kawaguchi and K. Wada, Investigation on people living with paro at home-evaluation of design for human robot interaction, 2010 IEEE Ro-Man, 2010, 470-475.

[22] W.-L. Chang, S. Sabanovic and L. Huber, Use of seal-like robot PARO in sensory group therapy for older adults with dementia, Proc. 8TH ACM/IEEE Int. Conf. Human-Robot Interact, 2013, 101-102.

[23] H. Robinson, B. Macdonald, N. Kerse and E. Broadbent, The psychosocial effects of a companion robot: A randomized controlled trial, J. Am. Med. Dir. Assoc. 14 (2013), 661-667.

[24] W. Moyle, M. Cooke, E. Beattie, C. Jones, B. Klein, G. Cook and C. Gray, Exploring the effect of companion robots on emotional expression in older adults with dementia: A pilot randomized controlled trial, J. Gerontol. Nurs. 39 (2013), $46-53$.

[25] P. Marti, M. Bacigalupo, L. Giusti, C. Mennecozzi and T. Shibata, Socially assistive robotics in the treatment of behavioural and psychological symptoms of dementia, The First IEEE/RAS-EMBS International Conference on Biomedical Robotics and Biomechatronics 27 (2006), 483-488.

[26] K. Roger, L. Guse, E. Mordoch and A. Osterreicher, Social commitment robots and dementia, Can. J. Aging 31 (2012), 87-94.

[27] C. Krishnan, D. Kotsapouikis, Y.Y. Dhaher and W.Z. Rymer, Reducing robotic guidance during robot-assisted gait training improves gait function: A case report on a stroke survivor, Arch. Phys. Med. Rehabil. 94 (2013), 1202-1206.

[28] M.M. Pinter and M. Brainin, Rehabilitation after stroke in older people, Maturitas 71 (2012), 104-108.

[29] D. Novak, A. Nagle, U. Keller and R. Riener, Increasing motivation in robot-aided arm rehabilitation with competitive and cooperative gameplay, J. Neuroeng. Rehabil. 11 (2014), 64-79.

[30] L.E.F. Graves, N.D. Ridgers, K. Williams, G. Stratton, G. Atkinson and N.T. Cable, The physiological cost and enjoyment of wii fit in adolescents, young adults, and older adults, J. Phys. Act. Health 7 (2010), 393-401. 